\title{
Study on Economies of Scale in Xinjiang Cotton Production Based on
}

\section{Small Sample Survey}

\author{
Yuyong $\mathrm{Xia}^{1}$, Qiong $\mathrm{Ma}^{2}$ \\ ${ }^{1}$ College of Economics and Management, Tarim University, Xinjiang, Alar, 843300, China \\ ${ }^{2}$ Tarim University, Xinjiang, Alar, 843300, China
}

Keywords: Xinjiang, Farmers, Cotton, Economics of Scale

\begin{abstract}
The economies of scale in cotton production should suit local conditions, and the mastering of Xinjiang farmers' cotton-growing situation has great significance to guide their planting and cultivation. By questionnaire, this paper researched the cotton production costs, economic efficiency planting acreage and others on Akesu in Southern Xinjiang, Changji in Northern Xinjiang and Turpan area in EasternXjinjiang, evaluating their cotton economies scale separately and collect the data to summarize the optimal production area in whole province. The results show that, in Changji city, with the increase of planting area, the cotton production costs present decrease trends at first and then increase in a U-shape, the $\mathrm{R}^{2}$ value is 0.332 , the optimal planting area is 176.7 acres, while Turpan sample shows that when the area is 71.9 acres can obtain the minimal input costs $623 \mathrm{RMB}$, and in Akesu, when the planting area is 72.57 acres will costs lowest 827 RMB per acre. And the largest optimal planting area is theChangji city in Northern Xinjiang. Analyzing the collected data, the results shows that the optimal economy planting area in overall province is 330 acreages, and corresponding lowest production costs is $913 \mathrm{RMB}$. It suggests that there exits differences between various regions of farmers economics of scale in Xinjiang and the planting area in northern part is larger.
\end{abstract}

\section{Introduction}

Xinjiang is the most important cotton production base in China. Since the mid-1990s, Xinjiang started to carry out the "one black, one white” strategy, and the status of cotton industry gradually increased in regional economy and household economy. The dependence of farmers household economy on cotton planting and interests is increased, and in some rural areas withhigh scale economy effect, the interests of cotton-growing not only become the main even whole source of family income, which directly influenced the rise and fall of farmer's income, county even regional economy. Therefore, it plays a significant role in improving farmer's income, stable the economy of Xinjiang and meet the demand of raw cotton in domestic enterprises and other aspects.

In the process of exploring agricultural development on the appropriate scale management, many experts and scholars studied from multi-angle and achieved many research fruits. Through the survey of Jiangsu farmers, Hu Jinzhi and HuangXianjin found that expanding the scale of land management can optimize agricultural production factors, improving the performance in certain levels. Li Gucheng etc. studied on Chinese farmers and found a significant positive correlation between the efficiency of agricultural production andtheir land scales. Liu Fengqin, used Stigler's survival test method to testifiedthe scale of land management issues and holds that there is no exact optimal models or scale boundaries, for parties will choose lowest transaction costs in the form of 
economic organization under different constraints, considering the situation that farmers can hold more than one job concurrently, thus the operation of small-scale farmers also meet the requirements of the economies of scale. Yao Jianfu argued that the size of farm was inversely proportional to productivity and small farms usually have high productivity, the output of per unit land or capital invests decreased with the expansion of farm scale.

It is obvious that the conclusions on agricultural economics of scale at home and abroad are different and there is few analysis on the efficiency of input-output on cotton planting. What's more, local cotton cultivation-production-sale process is vary from Xinjiang corps, it is necessary to research on the suitable cotton acreage based on local characteristics.

\section{Research materials and methods}

Research area. This investigation relates South, North and East part of Xinjiang, on administrative divisions include Changji city, Akesu County and Turpan city. These areas are the traditional cotton-growing areas.Superiority regional location and convenient transportation, the Eurasian Continental Bridge, 312 State Road and Wukui freeway crossed the five counties, developing regional agricultural, and mainly corps include cotton, wheat, oil plant, tomatoes, peppers and others. Using questionnaires, this paper obtained the input and output data in 2014 of 115 cotton farmers in the study area, including local farmers 80, accounting for $69.6 \%$, and 35 corps farmers, accounting for $31.4 \%$.

Research method. Research ideas and method in this paper are shown as follow.First, by collection related historical data and in-depth analysis through consult a large number of resources, from a macro level, describe the condition of state and Xinjiang cotton planting scale in the manner of traditional indicators. Second, surveying byinterview questionnaire, design the required questionnaires and collected data through field research. Third, measure and evaluation on the economies of scale of different planting sizes based on a linear regression, revealing the relationship between cotton input-output ratio and cotton planting acreage, finding out the law, analyzing whether there exits economies of scale or not. Finally, summarizing the above conclusions and to recommend.

Sample analysis. Among 159 valid questionnaires, males account for $87.50 \%$, females account for $12.50 \%$, for the head of the family is the main research objects, so male occupies a large proportion. They are more familiar with the usage of fertilizers, pesticides and mulch in cotton-growing, and we could accurately grasp farmer's production behavior by interviewing them. The average age of farmers being accessed is 42.57, most of them are young adults.

\section{Study on economics of scale of cotton-growing}

In this investigation and research, by compared and analyzedcotton-growing farmer's production behavior in Changji City, Turpan city and Aksu City, summarized itseconomies of scale of cotton-growing which is suitable on different areas in Xinjiang, and analyzed the overall scale of economies with a purpose to providing the best planting scales andobtain optimal economy benefits.

Relation between cotton-growing acreage and production costs in Changji city. The figure bellow is the economies of scale curve graph of cotton-growing area and production costs in Binhai town of Changji city in North Xinjiang. It shows, in Changji city, with the increase on planting area, cotton production costs presents a trend ofdecreased at first and then increased in a U-shape, quadratic function $\mathrm{R}^{2}$ value is 0.332 , the optimal planting area of 176.7 acres, in the vicinity of this value, the lowest production costs per acre is available, after exceeding this value, the costs 
gradually increased and economies of scale began to decline. Therefore, we believe that the economies of scale inBinhu county of Changji city are 176 acreages, which can obtain best economy values for Northern Xinjiang.

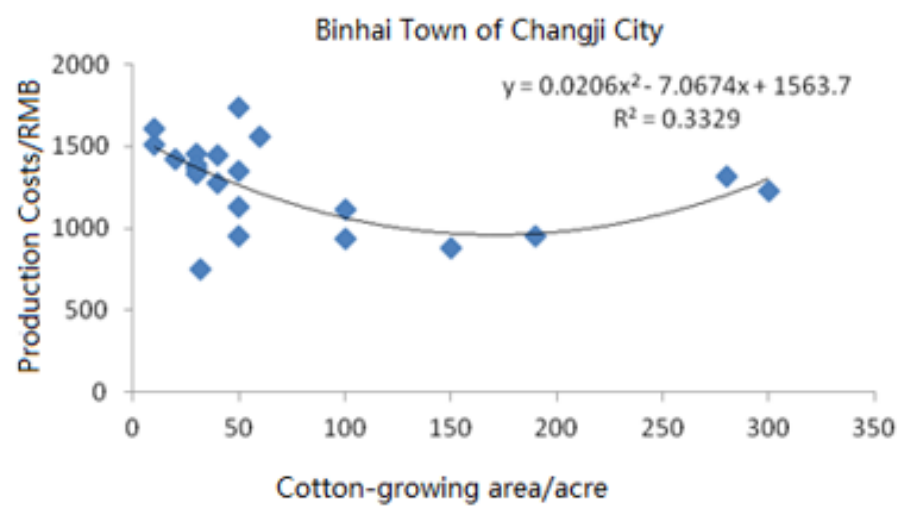

Fig 1 Relation between cotton-growing acreage and production costs in Changji city

Relations between cotton-growing acreage and production costs in Turpan city. The figure bellow is the economies of scale curve graph of cotton-growing area and production costs in Sanbao village of Turpan city. It shows the relation between production costs per acre and planting area present in U-shape, it means with the expanding of planting areas, the average costs decreased which is considered have economies of scale, until declined to a certain point, the long-term average costs began to rise, the costs curve slopes upward, then it is considered to be non-economies of scale. The figure shows, when the planting area reaches 71.9 acreages, it can realize minimal input costs of $623 \mathrm{RMB}$.

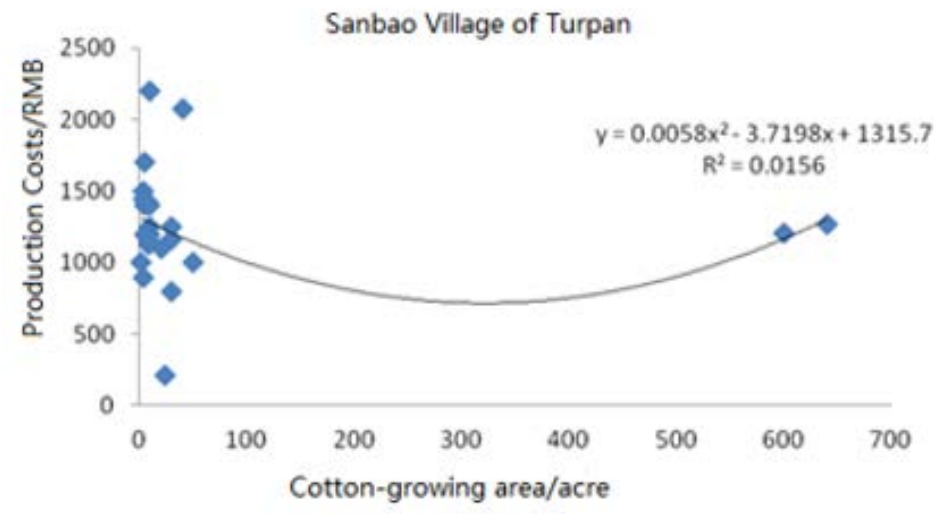

Fig 2 Relations between cotton-growing acreage and production costs in Turpan city

Relations between cotton-growing acreage and production costs in Akesukuche County. The figure bellow is the economies of scale curve graph of cotton-growing area and production costs in Akesukuche County. It shows the relation between production costs per acre and planting area present in U-shape, it means with the expanding of planting areas, the average costs decreased which is considered have economies of scale, until declined to a certain point, the long-term average costs began to rise, the costs curve slopes upward, then it is considered to be non-economies of scale. When the planting area reaches 72.57 acreages, it can realize lowest input costs of 827RMB and when the planting area increasing from 0 to 72.57 acreages, its corresponding costs is decreased, which trends to be increased once surpass this scale. 


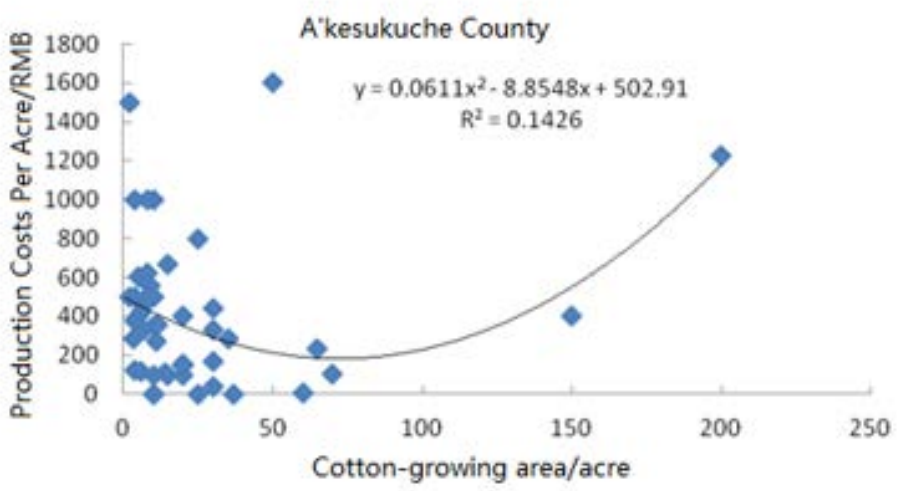

Fig 3 Relations between cotton-growing acreage and production costs in Akesukuche County

Relations betweencotton-growing acreage and production costs per acre (based on survey) in Xinjiang. According to the survey of these three areas, collecting the data and summarized the general economies of scale in these core areas of cotton-growing in overall Xinjiang. It shows the relation between production costs per acre and planting area present in U-shape, it means with the expanding of planting areas, the average costs decreased which is considered have economies of scale, until declined to a certain point, the long-term average costs began to rise, the costs curve slopes upward, then it is considered to be non-economies of scale. We can see that the U-shape is unclear, $\mathrm{R}^{2}$ is only 0.054 , the lowest point in U-shape which is the best type of economies of scale with 330 acreages of planting areas and corresponding lowest production costs 913 RMB, thus the optimal planting area of Xinjiang is 330 acres.

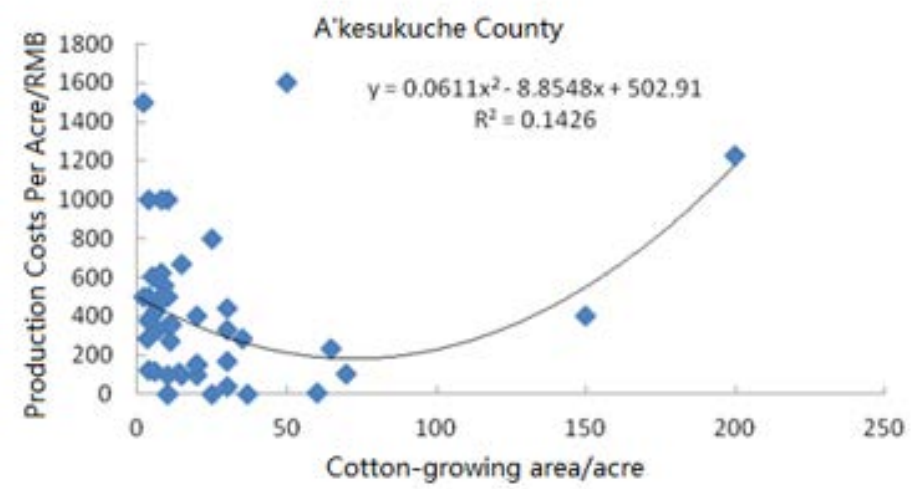

Fig 4 Relations between cotton-growing acreage and production costs per acre (based on survey)

\section{Conclusion}

The scale of cotton-growing in Xinjiang continues to make profits with the expanding of scale, but existing an optimal economies of scale, which is contained in these three represent regions respectively. It is related to many factors like family size, the number of labor force, the level of mechanism and others. Therefore, filtering and selecting the optimal cotton planting acreages not only reflectsthe appropriate scale of production in current, but also guidesother regions to realize optimization of cotton-growing to obtain maximum benefits. Taking Changji city of Northern Xinjiang for example, the optimal cotton area is about 170 acreages, it is to say this areas is suitable for small-scale cultivation and family as the unit in northern areas, achieving minimize of production costs and maximum profits. While for Turpan city of Eastern Xinjiang, they can realize lowest input costs when the planting areas is 362.5 acreages. In contrast, for Akesukuchecity of 
southern Xinjiang, their lowest input costs $872 \mathrm{RMB}$ can achieved when the planting areas is 72.57 acreages, which may be caused by limited survey samples, which mostly concentrated within 100 acres. Comprehensively analyzing all samples, we can found that, the optimum economies of scale in Xinjiang family-planting is 300 acres, which can obtain a higher incomes. While by analyzing the entire survey samples we know that, the planting scale in family production and management are mostly concentrated within 100 acres, indicating that the most units did not achieve optimal economies of scale planting. Therefore, this paper suggests following points to adjusting planting structures.

Large-scale cultivating mode of leasing cotton experts with payment. Encouraging the planting families with necessary funds and abilities to contract more land, and small family unitstransfer their lands to them. The one transferred their land can devote every efforts in other business categories to pursue better benefits and receive financial compensation from the land transfer fee. On the other hand, the transferee due to the expansion of cotton-growing areas and turning into a professional cotton households, fully display of their individual skills, improving the effective utilization of farm machinery, playing the advantage of breed and quality, improving labor productivity, increase net income and realizing economies of scale become the prominent developing directions. Thus, it is suggested to encourage contract land management rights by pay in cotton-growing areas, gradually expanding scale of planting by cotton experts.

Scientific, rational and timely adjust and optimize the agricultural economic structure of cotton areas. Through computational analysis, we clearly realized that economy structure has a direct or indirect impact on the scale of cotton cultivation, and the necessary cotton planting areas in different economy structures regions to achieving the same income levels is differ one from another. In some single economy structure of cotton-growing areas, their anchor of economic development is relatively weak, combining larger risks, difficulty in fully play the economic values of land, and hard to transfer labor forces, causing the large-scale and effective planting modes hard to achieve through internal rational and comprehensive adjustment. For this reason, this paper suggest the government in these areas to considering the scheme of adjusting and optimizing regional agricultural economic structure in the level of developing strategies as soon as possible to adapt to future development.

\section{References}

[1] Mao, S. Yu, S. WTO and China cotton. China Agriculture Press, Beijing, 2002. (In Chinese)

[2] $\mathrm{Hu}, \mathrm{C}$. Huang, X. Analysis on the influence of household land scale on the performance of agricultural production-based on the study of Tongshang County, Jiangsu Province. Journal of Agricultural, 2007, (6): 81-84. (In Chinese)

[3] Li, G. Feng, Z. Fan, L. Reallocation of labor in agricultural sector, the growth of rural agricultural and non-agricultural economics in China. South China Journal of Economics, 2007, (4): 22-23. (In Chinese)

[4] Liu, F. Study on the scale of Chinese agricultural land management-case analysis on small farmland business. Research on Financial and Economics Issues, 2003, (10): 60-65. (In Chinese)

[5] Yao, J. Large scale management and synthetic production efficiency of Chinese agriculture. Chinese Journal of Agricultural Resources and Regional Planting, 2000, 21(5): 19. (In Chinese) 